\title{
UAV-Based Optical Granulometry as Tool for Detecting Changes in Structure of Flood Depositions
}

\author{
Jakub Langhammer ${ }^{1, *}$, Theodora Lendzioch ${ }^{1}$, Jakub Miřijovský ${ }^{2}$ and Filip Hartvich ${ }^{1,3}$ \\ 1 Department of Physical Geography and Geoecology, Faculty of Science, Charles University in Prague, \\ Albertov 6, 12843 Prague, Czech Republic; theodora.lendzioch@natur.cuni.cz (T.L.); \\ hartvich@irsm.cas.cz (F.H.) \\ 2 Department of Geoinformatics, Palacky University in Olomouc, 17. listopadu 50, 77146 Olomouc, \\ Czech Republic; jakub.mirijovsky@upol.cz \\ 3 Institute of Rock Structure and Mechanics, Academy of Sciences, V Holešovičkách 94/41, 18209 Prague, \\ Czech Republic \\ * Correspondence: jakub.langhammer@natur.cuni.cz; Tel.: +420-221-951-363
}

Academic Editors: Eman Ghoneim, Jose Moreno and Prasad S. Thenkabail

Received: 5 February 2017; Accepted: 2 March 2017; Published: 7 March 2017

\begin{abstract}
This paper presents a new non-invasive technique of granulometric analysis based on the fusion of two imaging techniques, Unmanned Aerial Vehicles (UAV)-based photogrammetry and optical digital granulometry. This newly proposed technique produces seamless coverage of a study site in order to analyze the granulometric properties of alluvium and observe its spatiotemporal changes. This proposed technique is tested by observing changes along the point bar of a mid-latitude mountain stream. UAV photogrammetry acquired at a low-level flight altitude (at a height of $8 \mathrm{~m}$ ) is used to acquire ultra-high resolution orthoimages to build high-precision digital terrain models (DTMs). These orthoimages are covered by a regular virtual grid, and the granulometric properties of the grid fields are analyzed using the digital optical granulometric tool BaseGrain. This tested framework demonstrates the applicability of the proposed method for granulometric analysis, which yields accuracy comparable to that of traditional field optical granulometry. The seamless nature of this method further enables researchers to study the spatial distribution of granulometric properties across multiple study sites, as well as to analyze multitemporal changes using repeated imaging.
\end{abstract}

Keywords: granulometry; UAV; photogrammetry; fluvial geomorphology; alluvial sediment; image processing

\section{Introduction}

Granulometric analysis is a traditional, important, and ubiquitous method of describing sedimentary materials [1,2]. This analysis can be accomplished using a variety of techniques, including simple methods, such as classic sediment sieving, or more advanced methods of grain size measurements, such as those using X-ray or laser beams. However, most of these techniques do not work well with coarser clasts $(>2 \mathrm{~mm})$, which are categorized as fine gravel [3]. Collecting and analyzing a large number of gravel and boulder samples requires a large amount of time and effort. Because large quantities of bed material are removed in this method, it is invasive, which significantly restricts its application in areas where such manipulation is limited by environmental protections, private property, or settlement or industrial activities.

These limitations can be bypassed by using digital optical granulometry, which is an emerging method of image analysis [4]. In principle, optical granulometry identifies gravel clasts using calibrated digital imagery and consequently measures, sorts, and analyzes individual objects using standard granulometric approaches. Optical digital granulometry represents a huge advance in this field by 
enabling researchers to study the spatial distribution of fluvial processes, while dramatically reducing requirements for field surveys, sampling, and analysis.

Recent approaches to optical granulometric surveys, based on manual imaging using a digital camera and calibration frame, have attempted to measure the grain size distribution of selective sampling sites in the riparian zone [5]. This work presents a newly proposed technique to deliver seamless coverage of a given site (such as a series of point bars) by linking the methods of UAV photogrammetry and optical granulometry. This approach allows workers to analyze fluvial processes from various perspectives by establishing the distribution of phenomena in given areas, directions or transects, as well as by performing multitemporal assessments to detect changes and produce quantitative assessments.

UAV imaging allows researchers to obtain seamless, spatially-accurate geographic data, which can then be used to have a precise photogrammetric analysis of a dynamic river channel. UAV-based imaging, depending on the platform configuration, features high spatial accuracy that may surpass the traditional aerial photography, and high operability, which allows quick and operative imaging throughout a variety of complicated morphological conditions [6].

The aim of this study is to develop a framework enabling the non-invasive, seamless, and repeatable assessment of fluvial accumulations using optical granulometry. This method is based on the fusion of two rapidly developing applications of imaging technologies in the geosciences: UAV-based photogrammetry and digital optical granulometry. In particular, our study aims to: (1) determine the optimum flight parameters of UAV imagery to balance the parameters of imagery resolution and the extent of spatial coverage; (2) establish a procedure for the treatment of UAV-acquired imagery using optical granulometry; and (3) establish a protocol for the analysis of spatial distributions and temporal changes of granulometric properties across a point bar.

Low-altitude UAV photogrammetry, acquired using a multirotor platform and a calibrated digital camera, Structure-from-motion (SfM) approach, is used as a tool for image acquisition and the subsequent reconstruction of the 3D surface. Here, the experimental catchment of the Javoři Brook in the Sumava Mountains of Central Europe is selected as a study site, as it represents an example of a stream with highly dynamic fluvial processes, driven by repeated flooding resulting from rainfall runoff. Two campaigns of imaging using the UAV platform MikroKopter Hexa XL were performed in September 2014 and May 2016 in order to capture changes in sedimentation over the point bar after a series of winter floods in December 2015.

\section{Materials and Methods}

\subsection{Study Area}

This research focuses on the experimental basin of the Javoři Brook in the Sumava Mountains (Bohemian Forest) of Central Europe (Figure 1), which represents an unregulated stream with elevated dynamics of fluvial processes. This region is located in the headwaters of the mid-mountain range, which is hydrologically significant as a zone of frequent flooding. This region is known for its large-magnitude floods, including several recent extreme flood events in August 2002, and a series of heavy flash floods in 2009 [7].

This area has undergone significant recent changes in land use, settlement, and management practices. Mountains in this area were covered by medieval virgin forest until the 18th century, at which point the forest was converted to a forest spruce monoculture for the wood industry. As a result, the region has been repeatedly affected by bark beetle outbreaks, which have accelerated forest damage after windstorms $[8,9]$. 

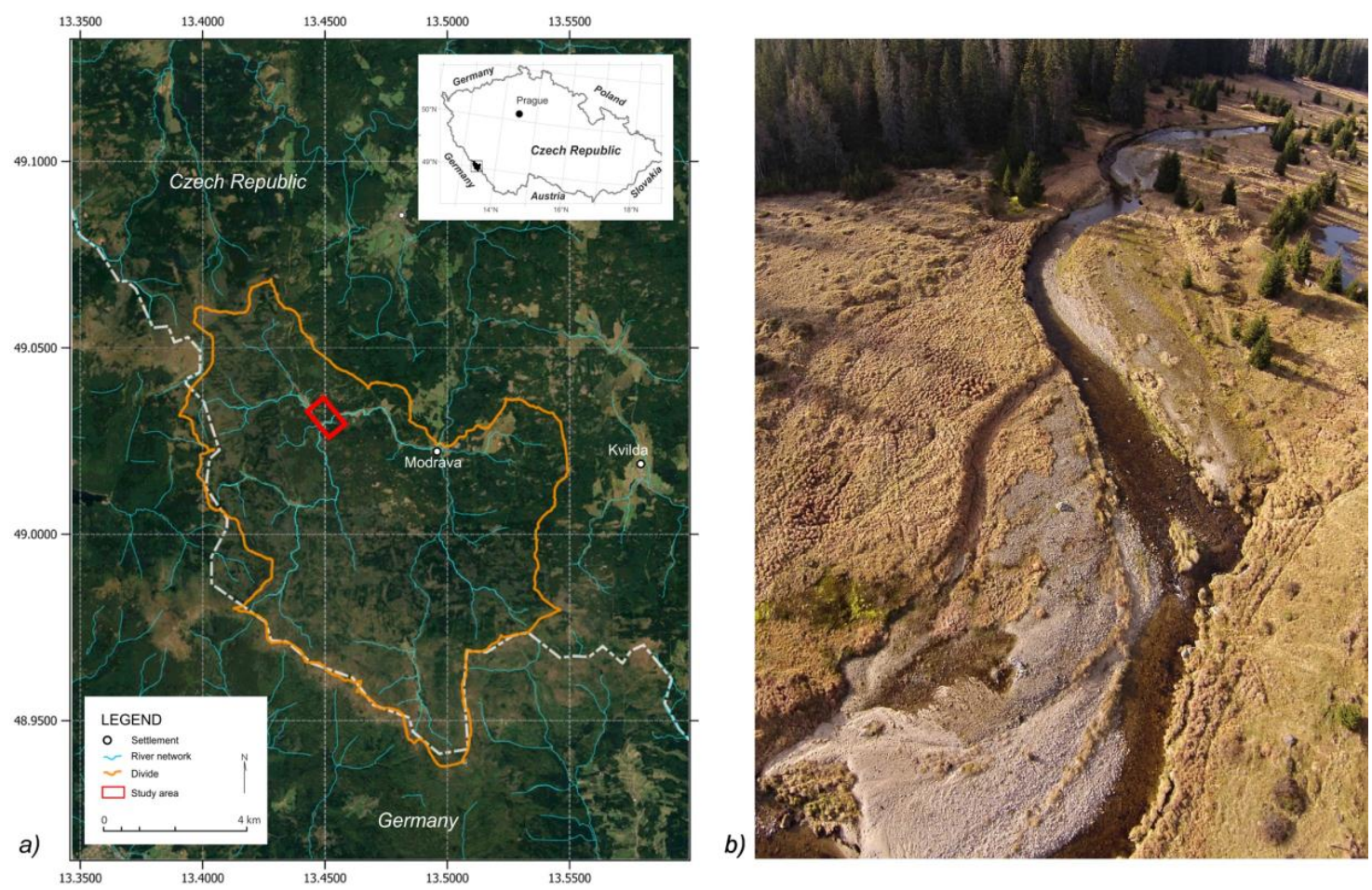

Figure 1. Study area: (a) Map of the study area; and (b) overview of the study site at Javoří Brook. Photo by J. Langhammer, 2014.

The high frequency of peak flow events, along with recent changes in land use, has established the elevated fluvial dynamics of this area [8]. Repeated floods in past years have helped researchers identify the recent hotspots of fluvial activity in the river system and to select study sites suitable for the multitemporal tracking of fluvial activity. The study site discussed herein comprises a point bar, located at the confluence of the Javoři and Roklanský Brooks, where fluvial processes were evidently started by a flood in June 2013 and heavily accelerated by an early winter flood in December 2015 (Figure 1b). A point bar located in the active meander, featuring active bank erosion and fluvial accumulations, is selected as the specific study site for this experiment. The studied meander is approximately $40 \mathrm{~m}$ long and $20 \mathrm{~m}$ wide. Fluvial processes in this study site were triggered by a flood in June 2013; since then, the meandering belt of the Javoří Brook has been subjected to intense fluvial activity [6].

\subsection{Digital Optical Granulometry}

Digital optical granulometry is a non-invasive technique, based on the semi-automated analysis of imagery of fluvial accumulation samples taken by a digital camera (Figure 2a). The principle of this technique is based on the recognition of individual objects from a digital image of the land surface. By using the selected detection techniques with a series of calibrated threshold parameters, the source surface is decomposed into individual objects and their geometric parameters are calculated $[10,11]$. To enable the calculation of geometric properties, the imagery must be calibrated to enable the derivation of the image scale.

As the information provided by this imagery only describes the surface of the sediment, information about the third dimension must be derived using other methods [12]. Here, we assume that, on each gravel clast, two longer axes, a and b, are visible, and that the third and shortest, c-axis, is oriented vertically and is thus not visible. The c-axis is then calculated using a characteristic coefficient for each rock type [4]. 


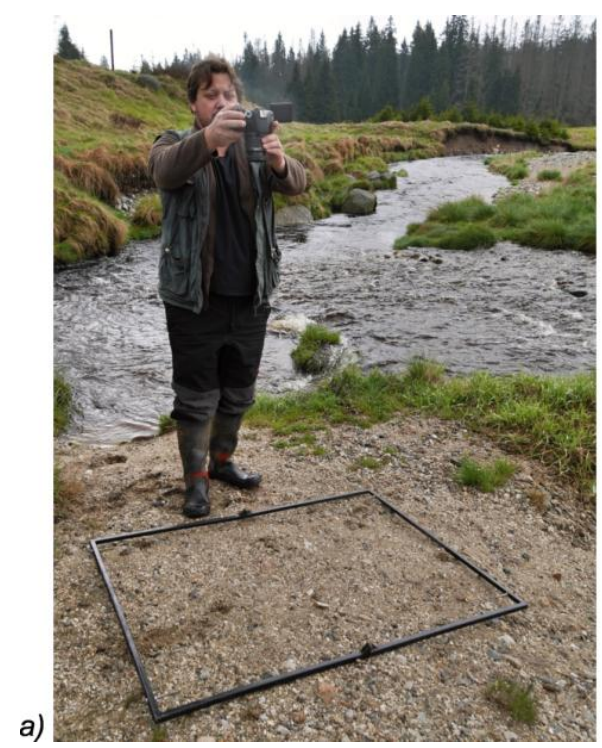

b)

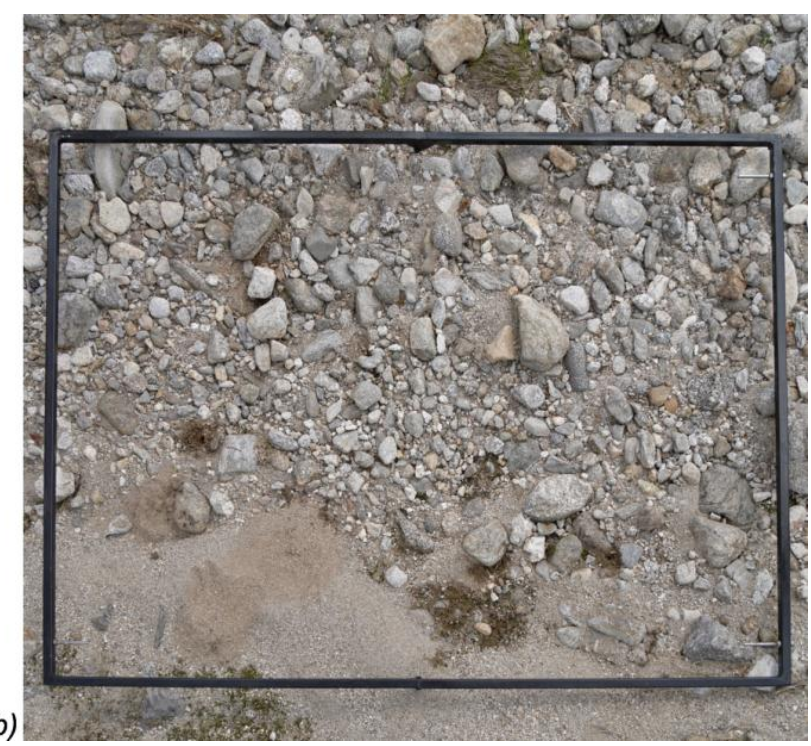

Figure 2. Digital optical granulometry: (a) Taking photographs of samples of gravel material; and (b) detail of the sample, taken with calibration frame. Photo by J. Langhammer, 2014.

Obtaining good image quality, particularly in terms of clearly defining scene properties and attaining high image resolution, is essential for successful data processing. A scene should comprise a clear, obstacle- and vegetation-free surface displaying gravel accumulation. All objects that are not subject of granulometric analysis, i.e., remnants of vegetation, woody debris or artificial obstacles are thus excluded from the scene to not distort the granulometric processing, based on automated object detection. As image processing and object identification are largely based on differences in contrast and tonality, the scene should contain an even distribution of light conditions without high contrasts between light and shadows, such as those present in the transition from sunlight to shadow under cover of vegetation or low elevation sun angles. Some methodologies and image analysis tools, such as the Sedimetrics digital gravelometer, require the application of an imaging flash to secure stable light conditions [5]. However, the application of a flash in wet riverine environments often results in the appearance of reflections and high contrast transitions that make analysis difficult.

Image resolution should allow for adequate classification and the distinction of fine particles. Generally, higher image resolutions and better camera quality yield better results. Images are typically taken from low altitudes with wide angles to capture the largest possible extent of sediment accumulation. In these conditions, lens quality is essential, as lenses with good parameters can minimize distortion and vignetting and can also reduce the amount of post-processing work needed.

The granulometric analysis in this study was processed using the BaseGrain 2.2 software, which was developed as a Matlab-based tool at ETH Zürich [13]. This image processing is based on a sequence of multiple steps, including those of grain recognition, classification, and analysis of the entire sample (Figure 3). The raw image, taken by field photography (Figure 3a) is preprocessed prior to this analysis. First, the image is corrected for distortion resulting from the use of a lens with a wide-angle focal length, which typically involves adjusting for the barrel/pincushion distortion. Advanced image editing software, such as Adobe Photoshop or Gimp, can then be used to compensate for distortion, rectify and rotate the image, and correct light conditions (Figure 3b). Establishing image processing parameters differs largely according to the applied software tool. However, common parameters necessary for quantitative analysis include the scaling of the image according to a calibrated frame or ruler (Figure 3c) and defining the threshold for identifying different categories of clasts. 

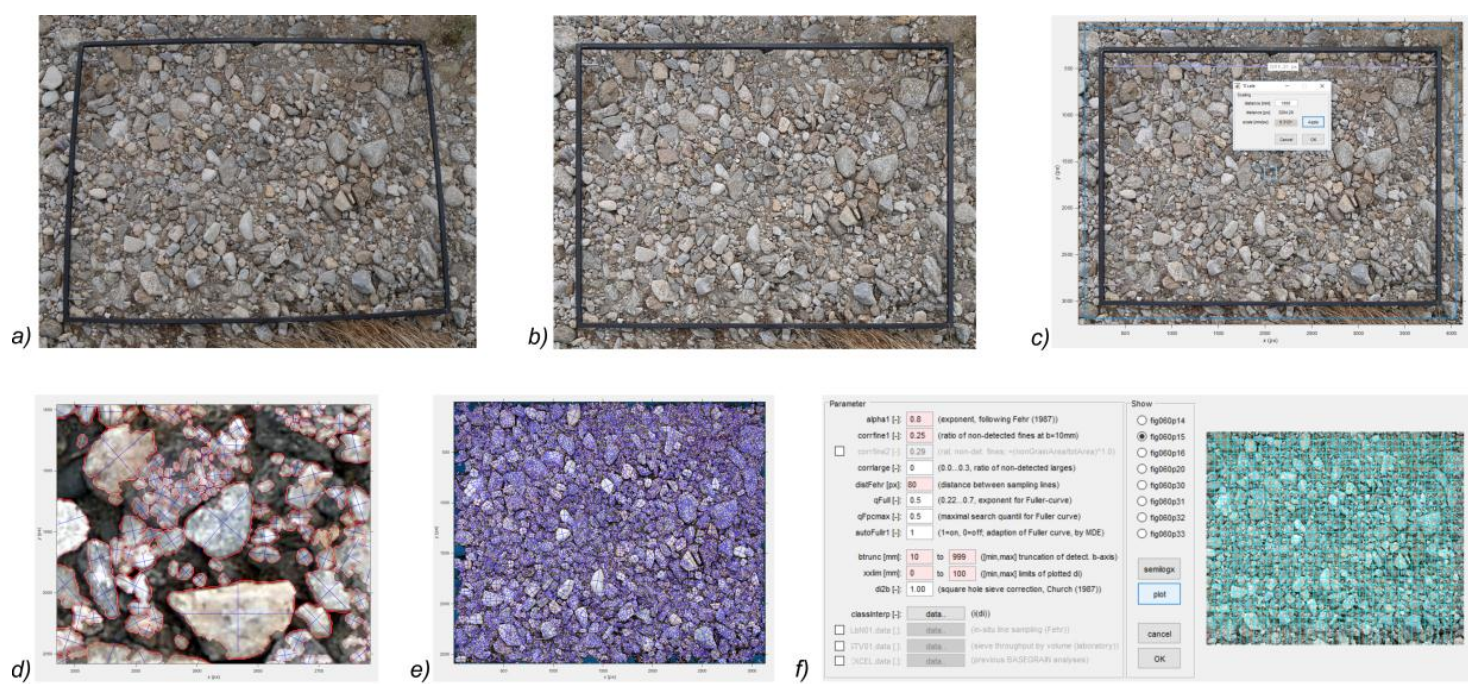

e)
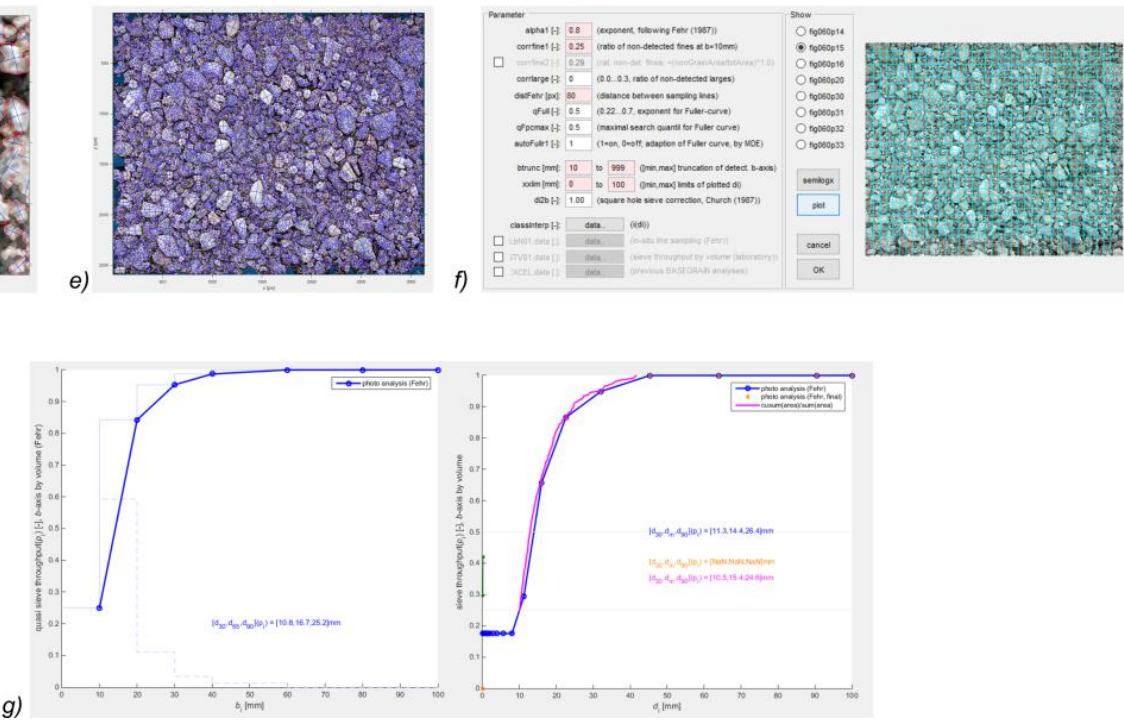

Figure 3. Workflow of optical granulometry image processing: (a) raw image; (b) rectified image prepared for analysis; (c) scaling and setting up of image properties; (d) identification of objects; (e) processed image with identified objects; (f) setting up classification and image analysis; and (g) resulting granulometric curves yielding results by number or volume of clasts with calculated diameter values.

After the calibration based on the identification of test objects (Figure 3d), the entire image is classified and is ready for further analysis (Figure 3e,f). By using the classified image with identified parameters of individual clasts, various kinds of granulometric analyses can be performed, using different grid scalings or methods of integration, based on the number of objects, volumes, or areas of individual clasts.

\subsection{UAV Photogrammetry}

UAV photogrammetry is a rapidly evolving discipline, combining the benefits of the vertical aerial view of aerial photogrammetry with the advantages of close distances and high levels of image detail provided by ground photogrammetry (Colomina and Molina 2014).

The basic principle of photogrammetric measurements is the use of geometric-mathematical reconstructions of the directions of photographic rays in a given image. To properly perform this aerotriangulation, which is the main goal of the photogrammetry process, it is necessary to constrain the elements of external and internal orientation [14]. Exterior orientation elements include the $X$, $\mathrm{Y}$, and $\mathrm{Z}$ coordinates of the camera on the platform, as well as the three camera tilt angles $(\omega, \phi$, and $\kappa)$. These coordinates and angles are measured relative to the ground coordinate system $[15,16]$. Reconstruction of the three-dimensional scene geometry is enabled by efficient image matching, based on identification of the corresponding pairs of points in the imagery. Methods of image matching, subject of intense development over the past decade, are typically based on the stereopairs matching or identification of correspondences in multiple images [17]. 
Significant shift in the field brought new image matching algorithms such as Structure from Motion (SfM) or Semiglobal Matching, enabling to automatically calculate exterior and interior orientation parameters from multiple viewpoints [18]. The SfM method, used in this study, stems on the basic principle of stereoscopic photogrammetry, that the 3D structure is resolved from the set of overlapping images. However, SfM diverges significantly from the traditional methods [19] while it allows for the acquisition and incorporation of unstructured images [20,21].

\subsection{Application in the Study Area}

\subsubsection{Design of Experiment and Imaging Campaign}

This study is based on information from two datasets acquired from the study site in May 2014 and June 2016. This time period reflects changes in the distribution of granulometric properties of accumulations over the point bar before and after a 20-year winter flood in December 2015 [22]. For each time slice, the study site was covered by seamless high-resolution orthoimagery, acquired by low-altitude UAV imaging (Figure 4).

Placed over the orthoimage is a regular network built for the granulometric analysis of selected sites. This network is designed as a regular $1 \mathrm{~m} \times 1 \mathrm{~m}$ grid spread over the meander (Figure 4 ). In this grid, transects have been identified across the point bar in order to assess the granulometric parameters of the alluvial sediment (Figure 4). As the entire system of the orthoimages and the grid are fixed in their coordinates, these grid fields can be used to collect repeated observations in order to construct a multitemporal assessment of changes over time.
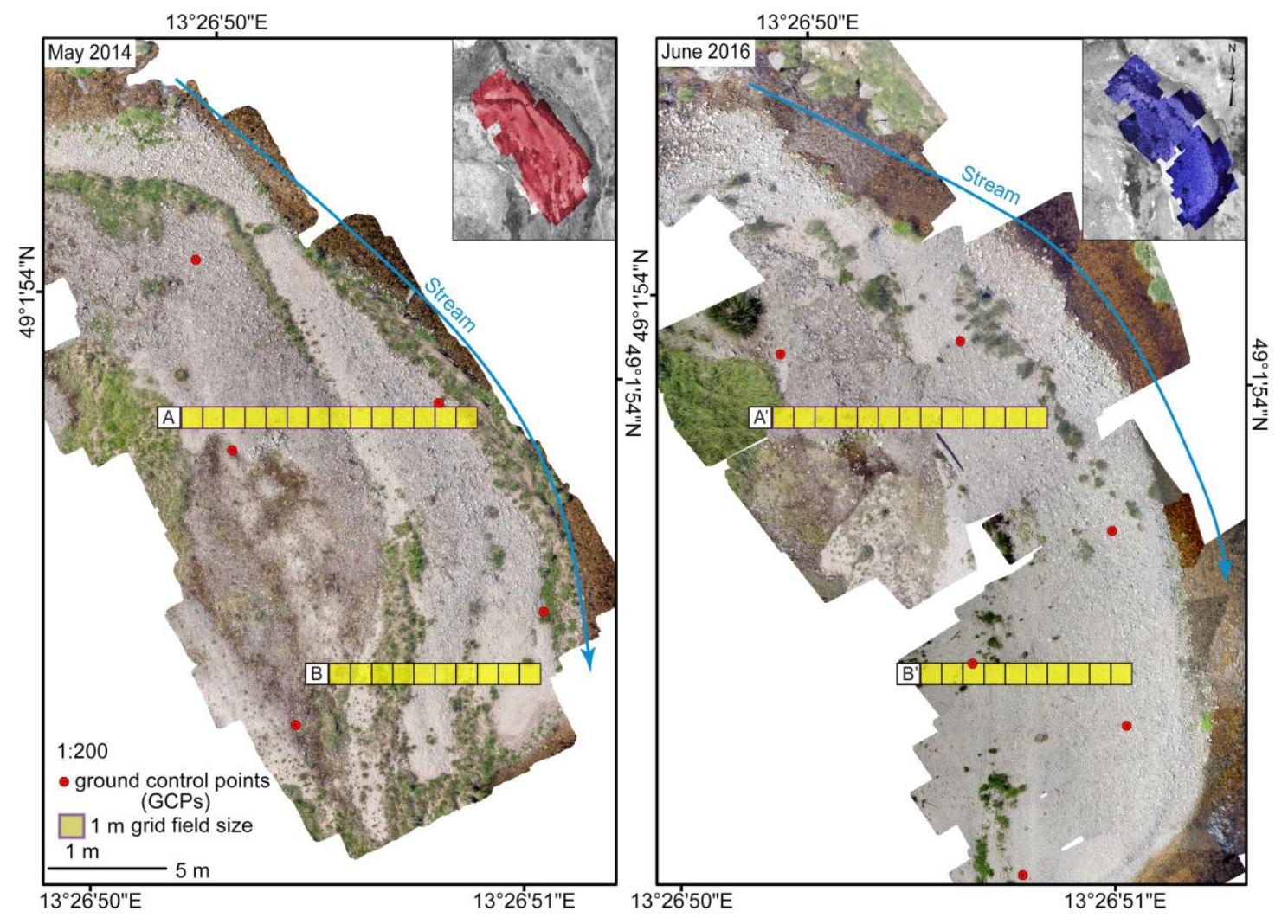

Figure 4. Gridded line transects over the orthoimages (May 2014 and June 2016), used for granulometric analysis.

Four multitemporal scans of the point bar in the meandering system of the Javoří Brook were taken in May 2014, September 2014, May 2015 and June 2016, covering the core area of the point bar (Figure 4), where the morphological changes occurred. Source imagery was acquired using a 
Mikrokopter Hexacopter UAV platform equipped with a Canon EOS 500 DSLR camera and a calibrated Voigtländer lens with a focal length of $20 \mathrm{~mm}$ (Table 1). The position of GCPs, marked by the small circles over the stones, was collected using the GNSS device Topcon Hiper II using the RTK method (Real Time Kinematic) with the virtual reference station (VRS) located in distance of $5 \mathrm{~km}$ from the area of interest. Correction data was obtained from the Czech GNSS reference network TopNet.

Table 1. Parameters of the imagery for two imaging campaigns.

\begin{tabular}{ccc}
\hline Parameter & $\mathbf{2 0 1 4}$ & $\mathbf{2 0 1 6}$ \\
\hline Imaging date & 23 May 2014 & 23 June 2016 \\
Number of images & 86 & 185 \\
Average flying altitude (m) & 7.9 & 4.4 \\
Ground sample distance (mm) & 1.7 & 0.96 \\
Number of ground control points & 6 & 5 \\
Image coordinate error (pix) & 0.3 & 0.1 \\
RMSE $_{Z}(\mathrm{~m})$ & 0.015 & 0.021 \\
\hline
\end{tabular}

During the 2014 imaging campaign, tests were performed to verify the optimal imaging parameters, realized at different levels of the flight altitude. The aim was to test the optimum flight altitude to balance the calculated imagery resolution, needed for granulometric processing with the practical aspects of the imaging campaigns in terms of spatial coverage, securing the imagery overlaps and keeping the altitude level. This imaging was performed at different altitudes, ranging from 3 to $12 \mathrm{~m}$ above ground level over the sampling site (Section 3.1).

Orthoimage mosaics of the study area for all campaigns were derived from the base dataset for consequent granulometric analysis. After its first imaging in May 2014, the point bar did not reveal any apparent changes in September 2014 and May 2015 due to the limited fluvial activity of the stream. However, a flood in December 2015 resulted in significant depositions over the studied point bar. Therefore, we used imaging performed in June 2016 to represent the second time horizon within the present analysis.

To obtain a detailed analysis of the grain size distribution across new and old accumulations within the profile of the point bar, two transects along the point bar in two different functional zones of the meander were chosen (Figure 4). The first transect A from 2014 (Figure 4) and the corresponding transect $\mathrm{A}^{\prime}$ from 2016 are located in the upper part of the meander, which features the coarser material at the entrance to the meander.

The second transect B from 2014 (Figure 4) and its corresponding transect B' from 2016 (Figure 4) are located in the lower part of the meander, covered by the fresh fluvial accumulations of sand and fine fractions. Granulometric analysis was performed for all fields of the grid across the transects at these two time horizons using the BaseGrain tool.

\subsubsection{Photogrammetric Processing}

The multi-stereo view image matching method was used to photogrammetrically process the data acquired by low-altitude UAV imaging, using the AgiSoft Photoscan Professional, version 1.2.6 Pro. Next, part of the image processing was processed using and Trimble INPHO software, version 7.1.3. From the Trimble INPHO package, three parts were used: DTMaster for DEM editing and validating, Orthomaster for orthophotos generating and OrthoVista for mosaicking as they offer significantly larger options for control of the DEM and orthoimage creation process.

The Agisoft Photoscan Pro and INPHO packages were combined at different steps in the photogrammetric processing workflow in order to obtain the highest-quality resulting orthoimages, sampled at extremely high-resolution values. Agisoft Photoscan Pro was used to construct the dense point cloud from pairs of aligned images and to derive the DEM using the Multi-view stereo matching 
method. The Trimble INPHO package was then used for accurate orthorectification and mosaicking to derive reliable orthoimages from the acquired data (Figure 5).

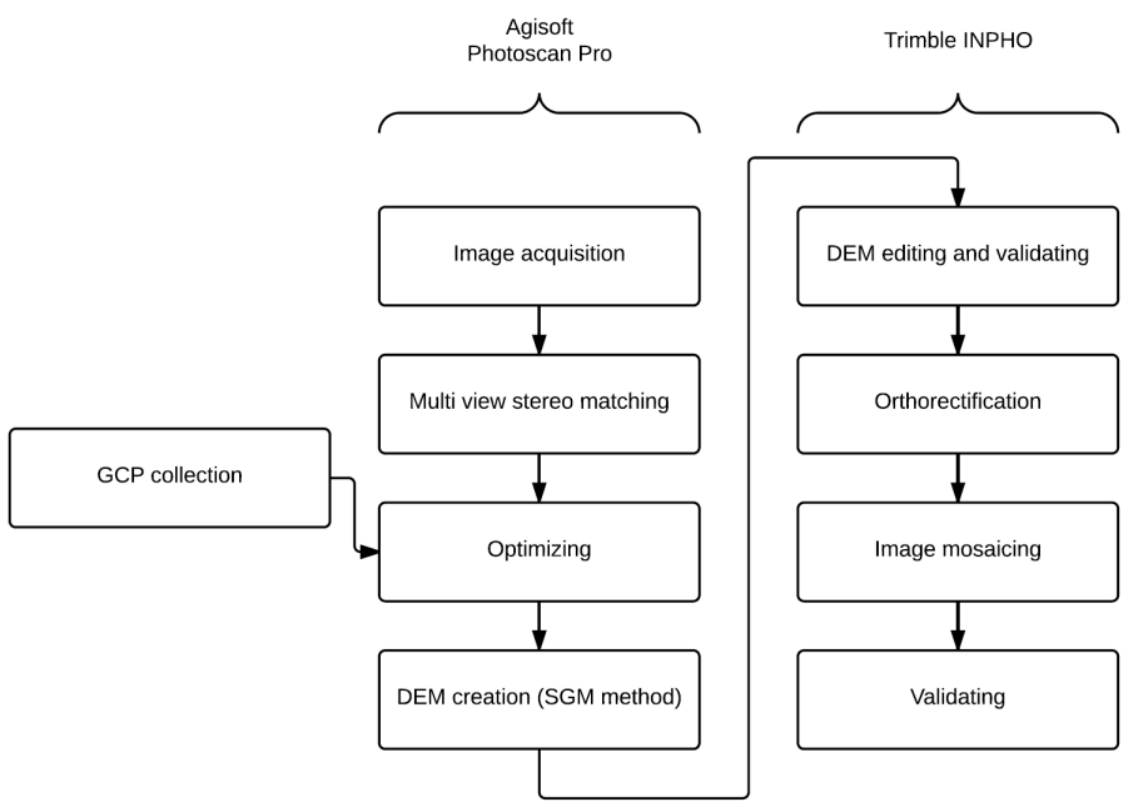

Figure 5. Workflow of photogrammetric image processing.

The input imagery consisted of images recorded in CR2 file format (raw format for Canon cameras), converted to 16-bit TIFF images. For image processing a PC station equipped with Intel Core I7-4770, 3.4 GHz and 16 GB RAM was used.

For both imaging campaigns, a high-resolution seamless orthomosaic with a ground sampling distance (GSD) of $1.5 \mathrm{~mm}$ was derived as the base spatial reference data product for further granulometric analysis (Table 1 ).

\subsubsection{Digital Granulometric Analysis}

The digital granulometric analysis was accomplished in two ways. First, a test transect was chosen for pre-testing the BaseGrain application to determine the optimum parameters using UAV-based imagery (Figure 6). Second, for further grain size analysis, different model transects (Figure 4) over the point bar were selected using these optimized parameters. For the test transect, we selected transect I from the regular grid built over the point bar (Figure 6) which contains a surface almost completely undisturbed by vegetation and continuously covers the zone between the stream and terrace. From these six grid fields, we selected five adjacent cells with no or minimum vegetation coverage (I-1-5, Figure 6).

In cells I-1-5, we performed granulometric analysis using the BaseGrain tool as mentioned in Section 2.2. Within each cell, the processing workflow described in Figure 3 was applied. For each of the selected grid fields, a semi-automated classification was performed (Figure 7). Default procedure parameters were applied at the beginning and consequently calibrated by checking objects and performing manual splitting and merging of inappropriately identified objects. This classification was applied to all grid fields using the same procedure, and grid sieving was accomplished using the Fehr methodology [23]. 


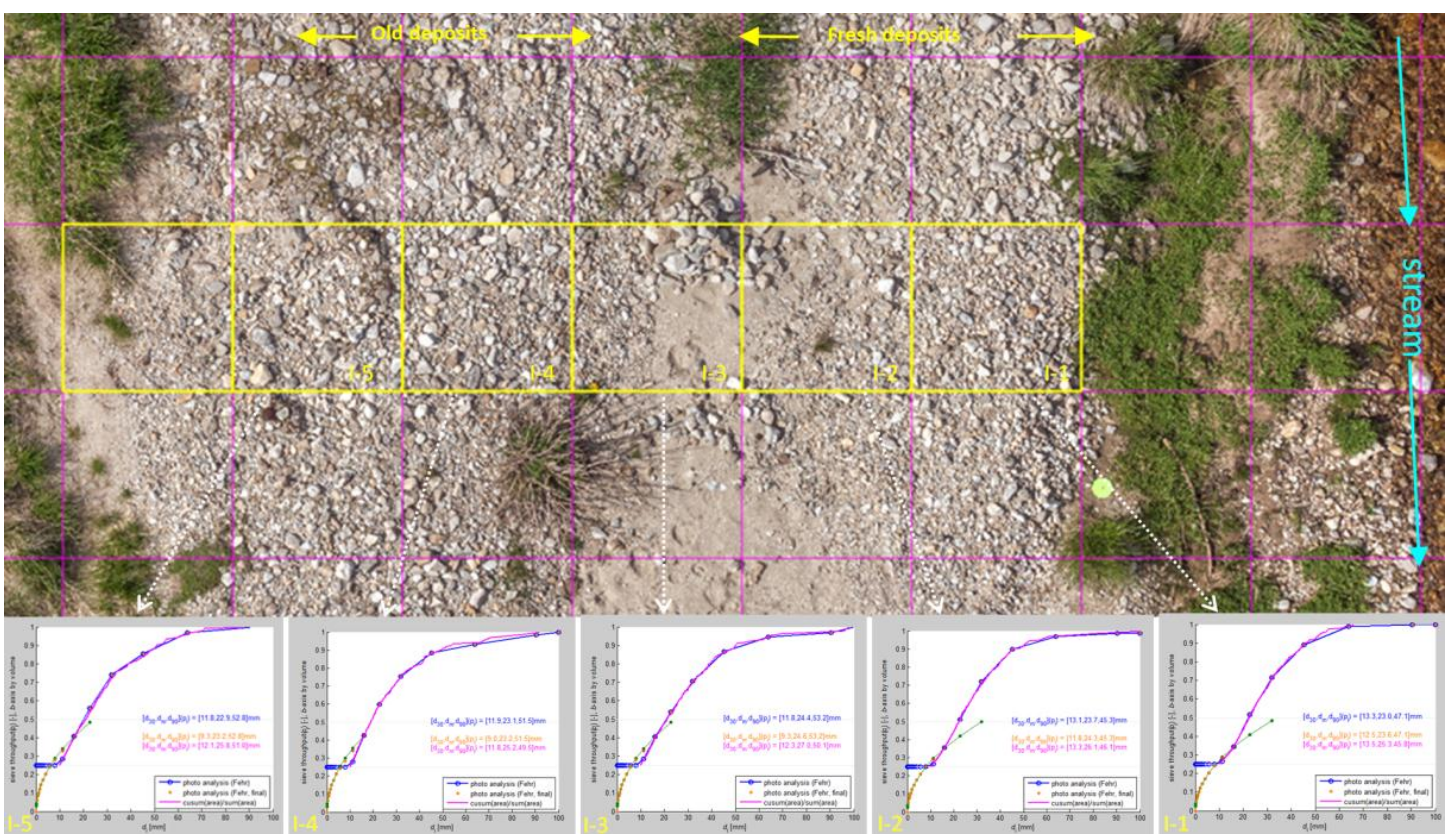

Figure 6. The principle of determination of the spatial distribution of granulometric parameters in the transect over the point bar.

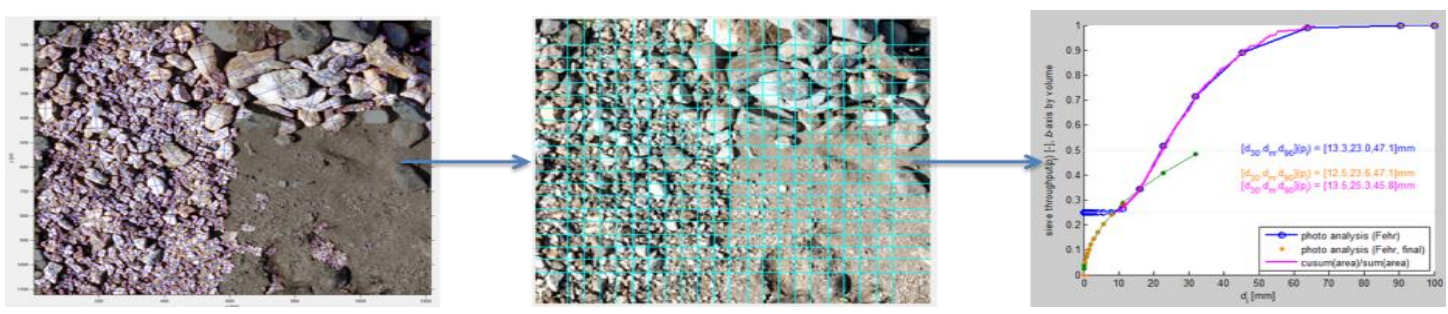

Figure 7. Calibration of the granulometric analysis of I-3 grid field by masking sand and excluding it from classification.

To achieve reliable results, the thresholds and parameters of this process should be automatically classified, as the conditions in each cell may vary. Eliminating parts of the image that do not contain data is vital for reliable classification. This parameterization applies mainly to interactive masking parts of the image that should not be classified, such as vegetation, shadows or sand, as well as the manual splitting or merging of objects that have been inappropriately identified by the automated procedure.

\section{Results}

\subsection{Determining the Optimum Parameters of UAV Imaging}

Acquisition of UAV imagery for optical granulometry was performed at low-level altitudes. At such conditions, imagery acquisition parameters should be carefully adjusted. To balance spatial resolution, flight parameters, and imagery volume, we tested these imagery acquisition parameters at various levels (Figure 7a,b) while obtaining imagery over a $75 \times 100 \mathrm{~cm}^{2}$ calibration frame used for conventional digital granulometry. We tested imagery parameters at various levels from 3 to $12 \mathrm{~m}$ above ground level (Figure 8). 

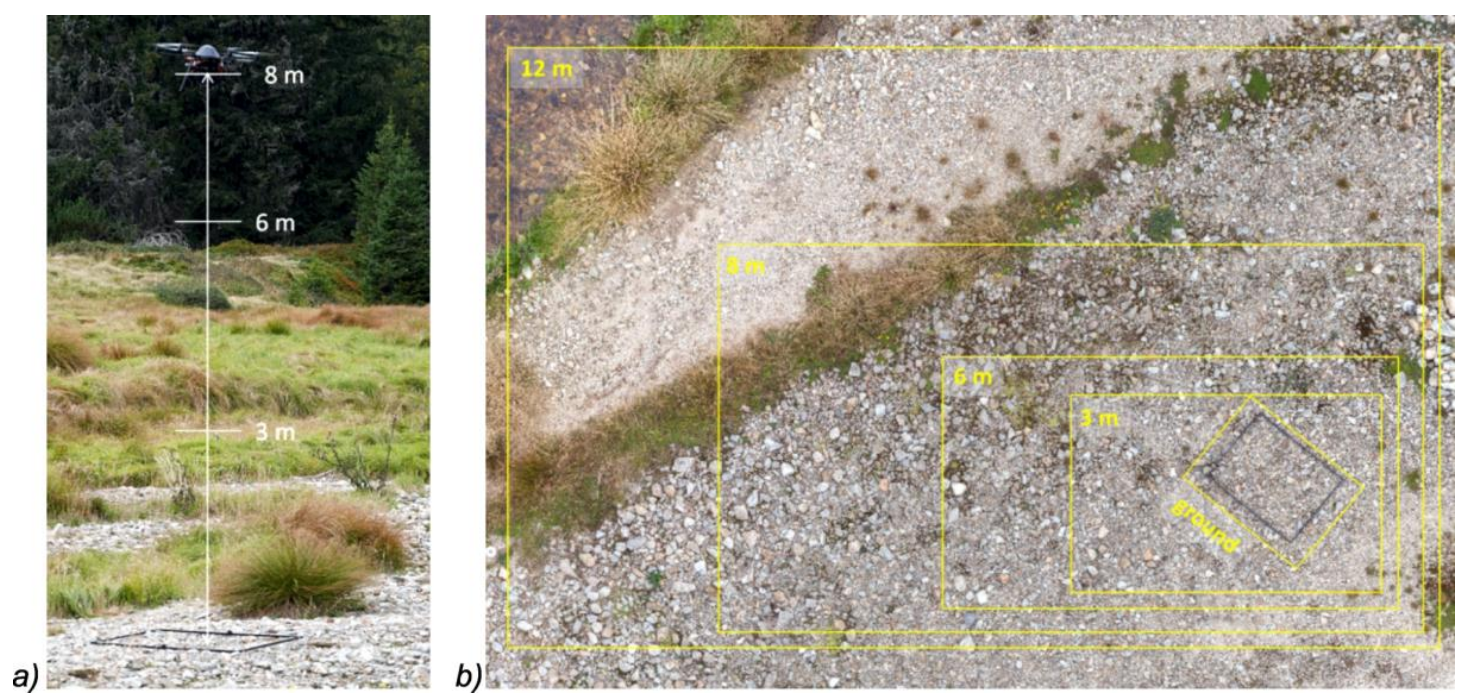

Figure 8. Determining the optimum flight altitude: (a) imaging the point bar at low-level flight altitudes; and (b) varying coverage at different levels of imaging altitudes.

The goal of determining the optimum imaging altitude is to balance several requirements of these datasets. First, all imaging should achieve an adequate resolution, at which the GSD should allow workers to adequately determine gravel categories for the purposes of their studies. We have selected the GSD of $1.5 \mathrm{~mm}$ as a base for the analysis value, enabling to assess the gravel size categories, occurring in the study site. As in the assessed montane stream the alluvial sediment is relatively coarse, with mean $D_{50}$ values ranging from 13.28 to $33.0 \mathrm{~mm}$ (Tables 2 and 3) the selected GSD values should secure reliable detection of the analyzed gravel structures features from multiple pixels.

Second, the chosen flight level should produce overlapping imagery of the study site, with no gaps. This is of special importance at low-level flight altitudes, as the accuracy of navigation sharply decreases with the flight level. At flight altitudes of approximately $5 \mathrm{~m}$ above ground level, the extent of the imaging scene is close to the accuracy of the GPS positioning devices of common UAVs, so that the reliability of the automatic, GPS-based navigation is at the edge of technical limits. This applies not only to the accuracy of $x-y$ positioning but also in keeping a consistent altitude above the ground throughout the entire scene. Moreover, in such conditions, manual navigation cannot be applied, as the limited extent of the scene does not allow for visual orientation and overlap control. Therefore, it is necessary to perform repeated imaging with the permanent cross checking of flight parameters during the flight in order to obtain consistent results.

Table 2. Grain size percentile diameter (a-axis; $\mathrm{mm}$ ) estimated using BaseGrain, and further parameters, such as min, max, mean and range for selected grain size percentiles and the median grain size $\mathrm{D}_{50}$ of transects $\mathrm{A}$ and $\mathrm{A}^{\prime}$.

\begin{tabular}{ccccccccc}
\hline \multirow{2}{*}{ Percentiles BaseGrain } & \multicolumn{4}{c}{ Transect A (2014) } & \multicolumn{4}{c}{ Transect A' (2016) } \\
\cline { 2 - 9 } & Min & Max & Mean & Range & Min & Max & Mean & Range \\
\hline $\mathrm{D}_{10}$ & 0.35 & 1.50 & 0.74 & 1.15 & 0.78 & 1.77 & 1.36 & 0.99 \\
$\mathrm{D}_{16}$ & 0.90 & 3.83 & 1.88 & 2.93 & 2.00 & 4.54 & 3.47 & 2.54 \\
$\mathrm{D}_{30}$ & 3.92 & 13.69 & 7.38 & 9.78 & 7.86 & 18.56 & 12.57 & 10.70 \\
$\mathrm{D}_{35}$ & 5.49 & 16.81 & 9.80 & 11.32 & 10.49 & 23.78 & 16.31 & 13.29 \\
$\mathrm{D}_{65}$ & 14.92 & 28.71 & 22.01 & 13.79 & 22.03 & 61.42 & 38.09 & 39.39 \\
$\mathrm{D}_{84}$ & 20.93 & 46.25 & 32.66 & 25.32 & 31.02 & 121.86 & 61.85 & 90.85 \\
$\mathrm{D}_{90}$ & 23.67 & 57.56 & 38.22 & 33.90 & 39.70 & 148.70 & 75.52 & 108.99 \\
\hline median grain size $\mathrm{D}_{50}$ & 11.60 & 25.01 & 18.06 & 13.41 & 19.18 & 54.26 & 33.00 & 35.08 \\
\hline
\end{tabular}


Table 3. Grain size percentiles diameter (a-axis; $\mathrm{mm}$ ) estimated using BaseGrain, and additional parameters, such as min, max, mean and range for selected grain size percentiles and for the median grain size $\mathrm{D}_{50}$ of transects $\mathrm{B}$ and $\mathrm{B}^{\prime}$.

\begin{tabular}{ccccccccc}
\hline \multirow{2}{*}{ Percentiles BaseGrain } & \multicolumn{3}{c}{ Transect B (2014) } & \multicolumn{3}{c}{ Transect B' (2016) } \\
\cline { 2 - 8 } & Min & Max & Mean & Range & Min & Max & Mean & Range \\
\hline $\mathrm{D}_{10}$ & 0.48 & 4.05 & 1.71 & 3.56 & 0.40 & 1.48 & 0.80 & 1.08 \\
$\mathrm{D}_{16}$ & 1.21 & 8.15 & 4.13 & 6.94 & 1.00 & 3.78 & 2.03 & 2.78 \\
$\mathrm{D}_{30}$ & 4.93 & 11.38 & 8.78 & 6.44 & 4.45 & 13.11 & 7.78 & 8.67 \\
$\mathrm{D}_{35}$ & 6.86 & 12.23 & 10.07 & 5.37 & 6.11 & 16.95 & 10.39 & 10.83 \\
$\mathrm{D}_{65}$ & 13.51 & 27.23 & 17.03 & 13.71 & 16.13 & 42.44 & 24.80 & 26.31 \\
$\mathrm{D}_{84}$ & 15.23 & 37.66 & 22.24 & 22.44 & 22.50 & 67.97 & 38.67 & 45.47 \\
$\mathrm{D}_{90}$ & 15.77 & 40.53 & 24.92 & 24.76 & 26.92 & 81.41 & 46.47 & 54.49 \\
\hline median grain size $\mathrm{D}_{50}$ & 9.69 & 17.33 & 13.28 & 7.64 & 12.94 & 35.40 & 20.74 & 22.46 \\
\hline
\end{tabular}

The third aspect is that of the total volume of the imagery resulting from the imaging campaign. The number of images needed to cover the study site, with given side and front overlaps, rapidly increases with decreasing flight altitude. A studied point bar, comprising a scene of $60 \times 30 \mathrm{~m}^{2}$, with a platform equipped with a $16 \mathrm{Mpx}$ DSLR camera and 70\% front and side overlap, imaged at a level of $8 \mathrm{~m}$ and with a GSD of $2 \mathrm{~mm}$, can be covered by approximately 154 images. Changing the altitude to $4 \mathrm{~m}$ increases the number of images needed to nearly 500 images. As photogrammetric processing demands large amounts of processing power, an unnecessarily excessive number of images can significantly increase the processing time and computing requirements of these analyses.

Here, we determine that an altitude of 4-8 m represents the optimum flight level in this study, producing a balanced series of image quality, coverage, and operability parameters. The optimal GSD, which is the key parameter for further granulometric processing, is below the threshold of the finest gravel category determined by granulometric analysis, which is the fine gravel with size of $2 \mathrm{~mm}$. Additionally, at this given flight level, the parameters of the imaging campaign remain manageable in terms of flight control, as well as the total volume of imagery that must be used for further photogrammetric processing.

\subsection{Grain Size Distribution across the Point Bar}

\subsubsection{Distribution of Grain Size Parameters over Transects A and A'}

The selected model transects, transect $\mathrm{A}$ and its corresponding transect $\mathrm{A}^{\prime}$, are crossing the point bar from the stream, moving through zones of fresh fluvial accumulations to those of old fluvial accumulations (Figure 4). The UAV-based images of these transects were acquired at $8 \mathrm{~m}$ flight altitude, where each grid field was photo-sieved individually by using the default value $\alpha=0.8$ used in BaseGrain. Following the manual splitting, merging or removal of misclassified grains, the calculated number of classified grains (per m) ranged from 104 grains $\mathrm{m}-2$ to 809 grains $\mathrm{m}-2$, with a mean of 447 grains $\mathrm{m}-2$ determined based on the results of both transects $\mathrm{A}$ and $\mathrm{A}^{\prime}$. Classified grain areas represent $34 \%$ to $82 \%$ of the total image area referring to transects $\mathrm{A}$ and $\mathrm{A}^{\prime}$. The residual void fraction represents grains with a-axis lengths of less than $10 \mathrm{~mm}$ or greater than $90 \mathrm{~mm}$ in diameter, as well as grains with boundaries that intersect the image boundary and those representing grass growth, the presence of wood fragments, and cast shadows.

The BaseGrain-derived grain size distributions of subsurface material extracted from each grid field along transects $\mathrm{A}$ and $\mathrm{A}^{\prime}$ are displayed in two different graphical presentations (Figure 9). The estimated diameters of the coarse fraction grain size percentiles (a-axis; $\mathrm{mm}$ ) from $\mathrm{D}_{10}$ through $\mathrm{D}_{90}$, as determined by photo-sieving and the median grain size $D_{50}$, are shown in Figure $9 a, c$. The seven percentiles shown therein $\left(\mathrm{D}_{10}, \mathrm{D}_{16}, \mathrm{D}_{30}, \mathrm{D}_{35}, \mathrm{D}_{65}, \mathrm{D}_{84}\right.$, and $\left.\mathrm{D}_{90}\right)$ indicate the sediment grain size (in $\mathrm{mm}$ ) for a particular "percent finer" value, which is used to compare individual values. The median grain size, $\mathrm{D}_{50}$, is discussed in greater detail in Section 3.3. The second graphical presentation displays a comparison of all cumulative frequency grain size distribution curves of both transects $\mathrm{A}$ and $\mathrm{A}^{\prime}$ 
(Figure 9b,d). The overall grain size distribution across the point bar of transect A demonstrates the strong dominance of coarser material $\left(\mathrm{D}_{65}, \mathrm{D}_{84}, \mathrm{D}_{90}\right)$, which appears to increase with decreasing distance from the riverbank (Figure 9a). However, the coarsest sediments are found on the first bar deposit (Bar 1; Figure 9a) and can be attributed to the remnants of alluvial accumulation transported by the flood in June 2013. In contrast, the overall grain size distribution of transect A' (Figure 9c) features even coarser material deposits along the point bar than are seen in transect A. Here, as well coarser material appears to increase with decreasing distance to the riverbank (Figure 9c), with one exception. An even stronger dominance of coarser material is observed at the second bar (Bar 2; Figure 9c), which can likely be attributed to the redistribution of sediments triggered by repeated flooding in December 2015 and April 2016.
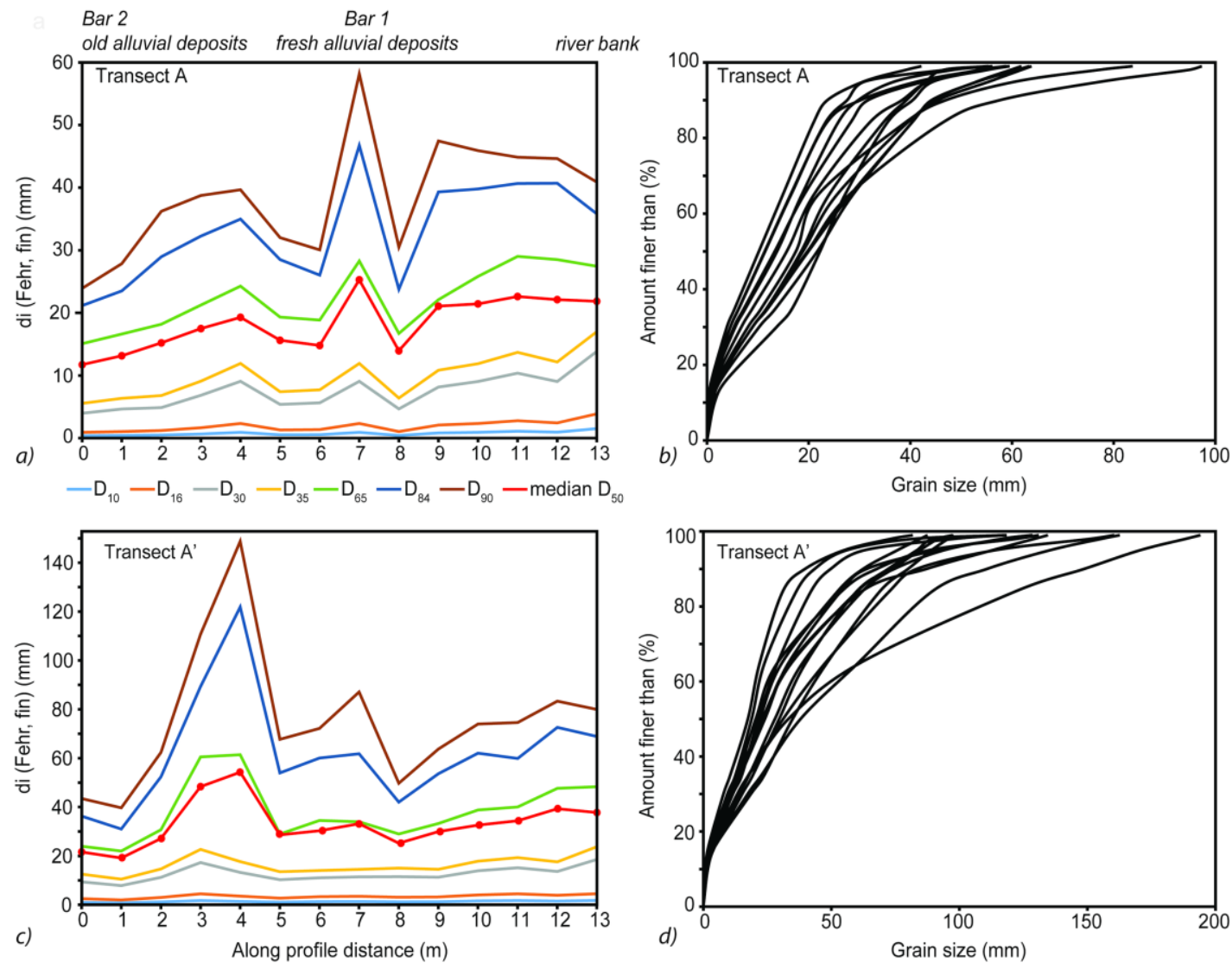

Figure 9. Analytical results of transects $A$ and $A^{\prime}$ along the point bar from May 2014. Grain size percentiles values (a-axis; $\mathrm{mm}$ ) including $\mathrm{D}_{10}, \mathrm{D}_{16}, \mathrm{D}_{30}, \mathrm{D}_{35}, \mathrm{D}_{65}, \mathrm{D}_{84}, \mathrm{D}_{90}$ and the median grain size $\mathrm{D}_{50}$, are estimated using BaseGrain versus distance $(\mathrm{m})$. D represents particle size (in $\mathrm{mm}$ ) and the subscripts denote each particular percentile. (a) Grain size distribution over the point bar and (b) cumulative frequency of grain size in transect A, (c) grain size distribution over the point bar and (d) cumulative frequency of grain size in transect $\mathrm{A}^{\prime}$. 
The areas under the grain size distribution curves vary based on their percentages of clay, silt, sand, and gravel sizes (Figure 9b,d). The obtained cumulative frequency grain size distribution curves for transect A show moderate variations between finer grains, but larger variations between coarser grains (Figure 9b). Similar profiles are also obtained for transect $A^{\prime}$ (Figure 9d), but with greater variations between coarser grains than are seen in transect A (Figure 9b). A summary of the statistics of distribution parameters min, max, mean, range, and the coefficient of determination $\left(r^{2}\right)$ values of percentile data and median grain size $\mathrm{D}_{50}$ of each grid field of transects $\mathrm{A}$ and $\mathrm{A}^{\prime}$ are shown in Table 2 .

The grain size of the surface layer, derived from the median $D_{50}$, varies from 12 to $25 \mathrm{~mm}$ for transect A, with a mean of $18 \mathrm{~mm}$ (Table 2); for transect $\mathrm{A}^{\prime}$, the median $\mathrm{D}_{50}$ varies from 19 to $54 \mathrm{~mm}$, with a mean of $33 \mathrm{~mm}$ (Table 2).

\subsubsection{Distribution of Grain Size Parameters over Transects B and B'}

The second model transects for this study are those of transect $B$ and its corresponding transect $\mathrm{B}^{\prime}$, which cross the point bar in the down part of the meander and reflect fresh fluvial accumulations of sand and fine fractions. The same approach as described above is adopted here. Transects B and B' contain the maximum coverage, which is maintained by both orthoimages, with all remaining grid fields removed from classification.

The density of classified grains range from 19 to 704 grains per square meter, with a mean of 432 grains per meter, as obtained for transects B and B'. Classified grain areas represented $15 \%$ to $72 \%$ of the total image area of transects B and $\mathrm{B}^{\prime}$. The residual void fraction represents similar grains with a-axis lengths less than $10 \mathrm{~mm}$ or greater than $90 \mathrm{~mm}$, induced by the same factors mentioned in Section 3.2.1. Visual representations of the BaseGrain-derived grain size distribution data of the subsurface material extracted from each patch across transects $B$ and $B^{\prime}$ are shown in the same manner as those of transects $A$ and $A^{\prime}$ (Figure 10). Likewise, photo-sieving is used to determine seven fraction grain size percentiles $\left(D_{10}, D_{16}, D_{30}, D_{35}, D_{65}, D_{84}, D_{90}\right)$ for transects $B$ and $B^{\prime}$, which are displayed in Figure 10a,c. One outlier grid field appears at a distance of $8 \mathrm{~m}$ due to its complete coverage by grass vegetation (Figure 10). The overall grain size distributions of transects B and B' (Figure 10a,b) reveal the dominance of finer material in comparison to the upper part of the riverbank. Here, the grain size gradually decreases from coarse to fine with increasing distance to the riverbank in transect $\mathrm{B}^{\prime}$ (Figure 10c). Consequently, the finest sediment deposits are found at the second bar (Bar 2, Figure 10c).

Likewise, the grid fields under the grain size distribution curves fluctuate depending on their percentages of clay, silt, sand, and gravel sizes. By comparing all cumulative grain size distribution curves along both transects B and B' (Figure 10b,d), it can be observed that the variation of finer-grained characteristics is higher in transect $B$ (Figure 10b) than it is in transect $B^{\prime}$. In contrast, higher variations in coarser-grained material are observed in transect $\mathrm{B}^{\prime}$. Table 3 presents the results of computed distribution parameters min, max, mean and range values of percentile data and median grain size $D_{50}$ of each grid field of transects B and $\mathrm{B}^{\prime}$. For each percentile, the grain size is calculated and compared between transects (Table 3). Here, the estimated median $D_{50}$ value varies from $10 \mathrm{~mm}$ to $17 \mathrm{~mm}$ for transect $B$, with a mean of $13 \mathrm{~mm}$. The median $D_{50}$ for transect $B^{\prime}$ ranges from $13 \mathrm{~mm}$ to $35 \mathrm{~mm}$, with a mean of $21 \mathrm{~mm}$. 

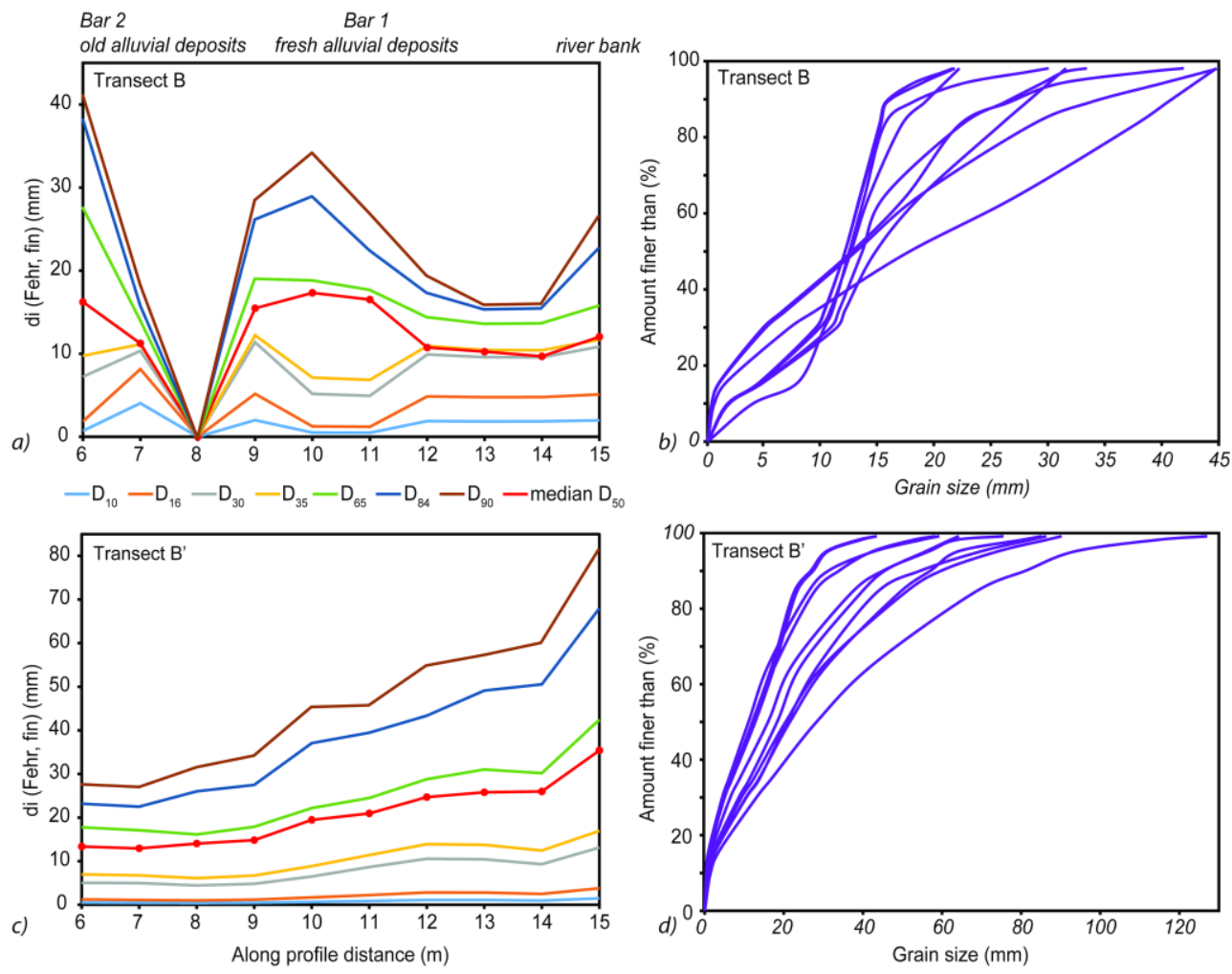

Figure 10. Analytical results of transects $B$ and $B^{\prime}$ along the point bar from May 2014. Grain size percentiles values (a-axis; $m m$ ) including $\mathrm{D}_{10}, \mathrm{D}_{16}, \mathrm{D}_{30}, \mathrm{D}_{35}, \mathrm{D}_{65}, \mathrm{D}_{84}, \mathrm{D}_{90}$ and the median grain size $\mathrm{D}_{50}$, are estimated using BaseGrain versus distance $(\mathrm{m})$. D represents particle size (in $\mathrm{mm}$ ) and the subscripts denote each particular percentile. (a) Grain size distribution over the point bar and (b) cumulative frequency of grain size in transect B, (c) grain size distribution over the point bar and (d) cumulative frequency of grain size in transect B'.

\subsection{Multitemporal Changes in Grain Size Distribution over the Point Bar}

In order to visualize multitemporal changes in grain size distribution, we used BaseGrain to calculate a simple linear regression of the median diameter $\mathrm{D}_{50}$ of all transects (Figures 11 and 12). Here, the median grain size is used because it is one of the most important parameters characterizing the effective particle size of a group of particles or of the grain size distribution curve, and therefore can be used to reasonably visualize grain size variability across the point bar. The median diameter $\mathrm{D}_{50}$ corresponds to the 50th percentile on a cumulative curve dividing its distribution into two equal parts, where $50 \%$ of the particles are larger and $50 \%$ are smaller than the typical value of $\mathrm{D}_{50}$. The estimated median $\mathrm{D}_{50}$ obtained from photo-sieving, applied to transects $\mathrm{A}$ (blue line) and $\mathrm{A}^{\prime}$ (orange line), shows significant differences in the grain size distribution of coarser grains between these two years (Figure 11). Additionally, the differences in the median $\mathrm{D}_{50}$ values are plotted by subtracting the median $\mathrm{D}_{50}$ values of the 2016 photo-sieved grid fields from their corresponding values from the 2014 photo-sieved grid fields, representing the midpoints by point markers (Figures 11 and 12). One error bar was plotting for each grid field (Figures 11 and 12). A positive value indicates that, during these two years, the photo-sieved area became coarser, whereas a negative value indicates that the photo-sieved area became finer. 


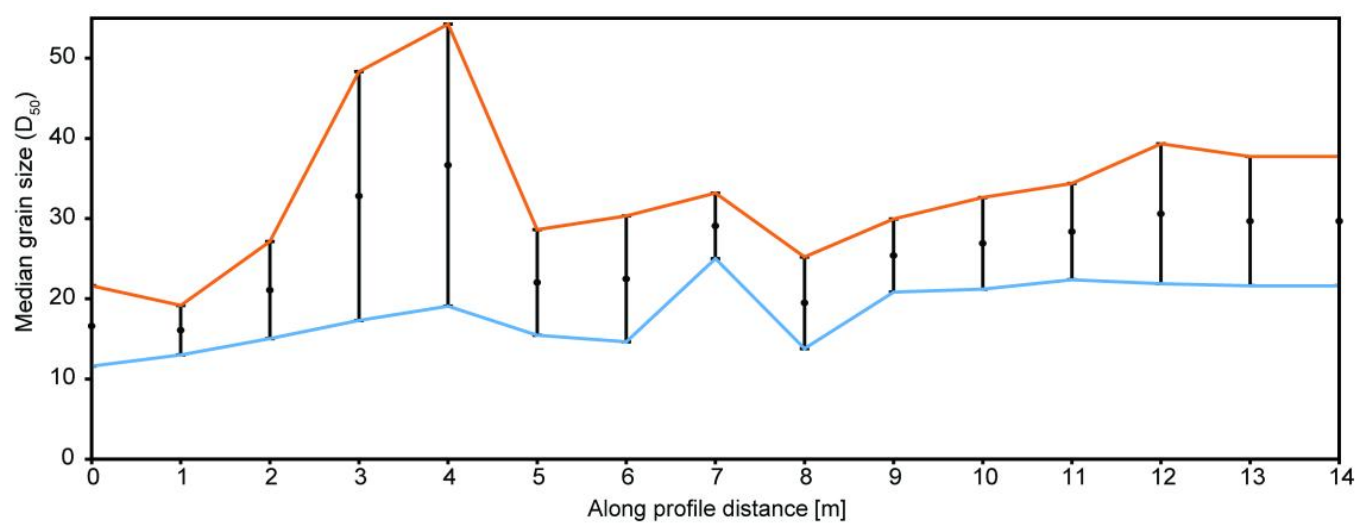

— median $\mathrm{D}_{50} 2016$ - median $\mathrm{D}_{50} 2014$

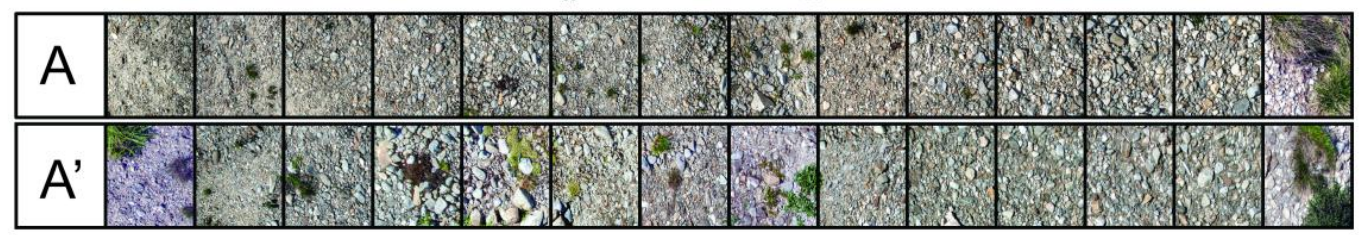

Figure 11. A simple linear regression of the median grain size $\left(D_{50}\right)$ distribution $(\mathrm{mm})$ from transects $A$ (blue line) and $\mathrm{A}^{\prime}$ (orange line) versus distance $(\mathrm{m})$. Error bars illustrate the difference between these two datasets.

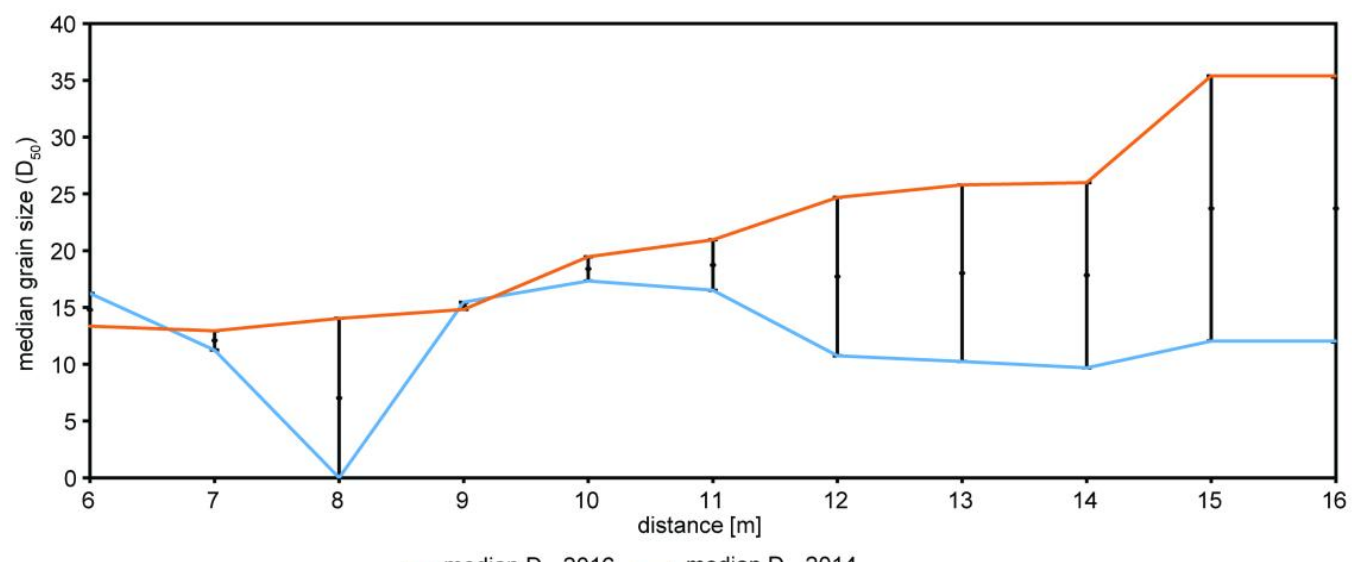

— median $\mathrm{D}_{50} 2016$ - median $\mathrm{D}_{50} 2014$

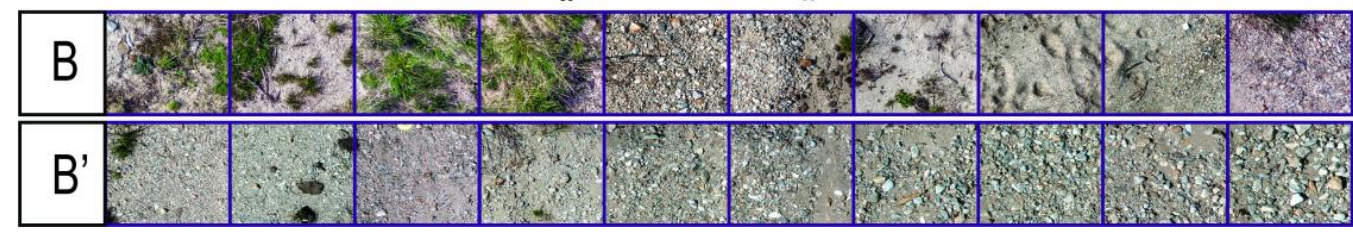

Figure 12. A simple linear regression of the median grain size $\left(D_{50}\right)$ distribution $(\mathrm{mm})$ from transects $B$ (blue line) and B' (orange line) versus distance (m). Error bars illustrate the difference between these two datasets.

The majority of transect A records a median grain size of $<18 \mathrm{~mm}$. Within this fraction, analyzed grid fields with smaller grain sizes $(<13 \mathrm{~mm})$ are largely confined to areas that are further away from the riverbank (Figure 11), whereas areas located closer to the river channel are characterized by larger $\mathrm{D}_{50}$ values $(>18 \mathrm{~mm})$. In contrast, the majority of transect $\mathrm{A}^{\prime}$ records a median grain size of $<35 \mathrm{~mm}$. Within this fraction, grids with the lowest $\mathrm{D}_{50}$ values $(<20 \mathrm{~mm})$ are limited to areas that are further away from the riverbank, whereas areas storing coarser material (e.g., bars) or areas that are closer to the riverbank are characterized by relatively larger $D_{50}$ values ( $>35 \mathrm{~mm}$ ) (Figure 11). 
The median $D_{50}$ values of transect $A^{\prime}$ (orange line) increase over the upper part of the meander (Figure 11). The differences between the median $D_{50}$ values of 2014 compared to the median $D_{50}$ values of 2016 are significant along the whole point bar (Figure 11).

Within this fraction, analyzed grid fields with smaller grain sizes $(<13 \mathrm{~mm})$ are found in areas that are further away from the riverbank (Figure 12), whereas larger median $D_{50}$ values $(>30 \mathrm{~mm}$ ) characterize areas that appear closer to the river channel. In contrast, the majority of transect $B$ possesses median $D_{50}$ values of $<13 \mathrm{~mm}$ (Figure 12). Within this fraction, transect areas with the lowest $\mathrm{D}_{50}$ values $(<14 \mathrm{~mm})$ appear in areas that are further away from the riverbank, whereas relatively larger $D_{50}$ values $(>16 \mathrm{~mm}$ ) characterize areas where coarser material is stored (e.g., bars) or in areas that are closer to the riverbank (Figure 12). Here, the majority of transect B' records a median grain size of $<21 \mathrm{~mm}$.

\section{Discussion}

The repeated granulometric analysis enabled to analyze the changes in the structure of alluvial depositions, resulting from the high flow events in the meandering system of the assessed montane creek. According to photo-sieving, the sediment in both transects $\mathrm{A}^{\prime}$ and B' (Figures 11 and 12) significantly increase, especially in the values from the 2016 dataset. In both transects $A^{\prime}$ and $B^{\prime}$, coarser material appears to increase with decreasing distance from the riverbank, based on their median grain size $\mathrm{D}_{50}$ distributions. This suggests that the upper and, to an even greater extent, lower parts of the meander became replenished by a coarser sediment supply over the time period of interest in this study (Figures 11 and 12). During each high-flow condition, new depositions are formed on the point bar, thus allowing coarse-grained surface sediments to be deposited. The accumulation of finer sediments can be explained by the low-energy environment in the area. All monitored transects in this study, are spots of active bank erosion and accumulations, corresponding to the distribution of traces of the past fluvial processes, which are triggered by floods with recurrence periods of 2-5 years [6].

Designing and testing of a workflow for UAV granulometry enabled analyzing the potential of fusion of two rapidly evolving computer vision techniques: the optical granulometry and UAV photogrammetry. Optical digital granulometry is still a relatively new survey technique with limited applications to fluvial geomorphology, although its theoretical principles and software applications have been tested [24]. Despite the fact that the principle of this method is based on a simplified approach, in which only 2D images of clasts are used as data sources for this analysis, its applications in different environments have demonstrated the solid performance and practical usability of the approach [10,24].

The main benefits of digital optical granulometry are those demonstrating the high operability of the method, its fast data collection on large areas and its non-invasiveness. The limitations of this method are rooted in the simplification of the clast schematization in two-dimensional space. Although various studies have statistically proved the reliability of this technique, irregular conditions and local distributions of fluvial accumulations may limit its performance.

Because optical granulometry is based on image analysis, the quality of the source imagery is the key factor in determining the success of the classification. There are several aspects controlling image quality, including the quality of the digital imagery, light conditions, and the appropriate composition of a scene. High physical image resolution is required to reliably identify objects of all gravel categories and to efficiently separate them from background material, such as sand or mud. Properties of image quality, including no or low image compression, no or low distortion, and uniform light conditions, are thus essential for the proper identification of objects and their shapes.

The goal of this study is to develop and test methodology for coupling optical granulometric surveys with UAV imagery to extend the potential of each approach. The key goal is to overcome the limitations of field surveys, based on selective sampling in given spots. Use of the UAV imaging platform allows us to acquire seamless ultra-high resolution imagery, which can be consequently analyzed using the same method that is used in field optical granulometry. 
To accomplish this, it is necessary to reduce several technical limitations in order to differentiate UAV-based analysis from field surveys. Field optical granulometric surveys typically rely on the use of a calibration frame for sampling study sites. This workflow is reflected by its software applications, in which some of them (such as the Sedimetrics digital gravelometer), strictly require the use of a calibration frame for imaging to calculate a scale and automatically correct image distortion [5]. To use UAV imagery as a data source, it is thus necessary to use software that does not require a fixed calibration frame for auto-corrections. However, the missing spatial information in the imagery calculated from a calibration frame must be replaced by providing accurate and spatially consistent spatial scales.

To enable accurate spatial georeferencing of ultra-high resolution imagery, the UAV data collection must be adjusted using ground control points positioned with geodetic accuracy and maintaining all steps of the photogrammetric workflow at a consistent level of precision.

A significant issue affecting both the quality of results and the operability of the survey is that of the optimum UAV image acquisition parameters needed to secure satisfactory optical resolutions of imagery, obtain seamless spatial coverage of imaging campaigns, and retain a reasonable total volume of imagery used for photogrammetric processing.

The optical resolution of the imagery has a direct effect on the GSD of the generated orthoimage. As the lower threshold for grain size identification is set at two millimeters [25], it is preferable to use a lower optical resolution of the source imagery in order to resolve the smallest clasts with greater certainty. Higher image resolution can be achieved in two ways: reducing the flight altitude or increasing the sensor resolution. In this study, we use a DSLR, equipped with a $16 \mathrm{Mpx}$ sensor and a $20 \mathrm{~mm}$ prime lens, which enables us to achieve a resolution of $1.5 \mathrm{~mm}$ (which was deemed satisfactory to assess this region) at a level of $6 \mathrm{~m}$. Based on previous experience with repeated field campaigns at such conditions, we consider this altitude to be a practical limit for operating an imaging campaign. At lower altitudes, the horizontal, and especially vertical, positioning of the drone becomes burdened by errors, and there is an increased risk of obtaining inconsistent or incomplete results.

In contrast, using sensors with higher optical resolutions can improve both quality and operability. When considering cameras with lenses of equivalent focal length, an image resolution of 1.4 millimeters achieved at $6 \mathrm{~m}$ using a $16 \mathrm{Mpx}$ camera can also be reached at $8 \mathrm{~m}$ with a $24 \mathrm{Mpx}$ sensor or even at $12 \mathrm{~m}$ with a $50 \mathrm{Mpx}$ full-frame camera (Table 4). Ultra high-resolution sensors enable workers to achieve higher flight altitudes while covering larger areas, maintaining flight parameters, and securing overlapping imagery. In case there is a desirable increase of the flight altitude, there is possible to use a prime lens with longer focal length. Then it is possible to keep same the spatial resolution and image footprint size but with higher flying altitude. Camera resolution and appropriate lens selection thus appear to be the key elements for acquiring images at required levels of resolution and spatial consistency.

Table 4. Effects of variable flight altitude and sensor resolution on ground sampling distance. GSD calculated using Pix4D calculator [26].

\begin{tabular}{|c|c|c|c|c|c|c|}
\hline Camera and lens & $\begin{array}{l}\text { Sensor Resolution } \\
(\mathrm{Mpx})\end{array}$ & $\begin{array}{l}\text { Sensor Size } \\
(\mathrm{mm}) *\end{array}$ & $\begin{array}{c}6 \mathrm{~m} \text { GSD } \\
(\mathrm{mm})\end{array}$ & $\begin{array}{c}8 \mathrm{~m} \\
\text { GSD/Scene } \\
\text { Size }\end{array}$ & $\begin{array}{c}12 \mathrm{~m} \\
\text { GSD/Scene } \\
\text { Size }\end{array}$ & $\begin{array}{c}16 \mathrm{~m} \\
\text { GSD/Scene } \\
\text { Size }\end{array}$ \\
\hline Canon EOS 500D, $22 \mathrm{~mm}$ lens & 15.5 & $22.3 \times 17.9$ & 1.33 & 1.77 & 2.66 & 3.54 \\
\hline Nikon D3300, $22 \mathrm{~mm}$ lens & 24.2 & $23.5 \times 15.6$ & 1.11 & 1.41 & 2.12 & 2.83 \\
\hline Nikon D800E, $35 \mathrm{~mm}$ lens & 36.8 & $35.9 \times 24$ & 0.83 & 1.11 & 1.66 & 2.22 \\
\hline Sony A7R II, 35 mm lens & 42.4 & $36 \times 24$ & 0.77 & 1.03 & 1.54 & 2.06 \\
\hline Canon EOS 5DS, $35 \mathrm{~mm}$ lens & 50.6 & $36 \times 24$ & 0.71 & 0.95 & 1.42 & 1.89 \\
\hline
\end{tabular}

* Sensor parameters are given according to the specifications, provided by the manufacturers.

The aforementioned results are, however, related to the common UAVs and cameras, used in research and mapping. Application of the professional-grade large sensor cameras (i.e., PhaseOne XF with a $100 \mathrm{Mpx}$ sensor) and respective imaging platforms, able to assure high endurance 
while operating with heavyweight devices, has great potential with diverse applications i.e., in geomorphological and regolith mapping or industrial applications, i.e., in mining.

The photogrammetrical treatment, which is performed at millimeter-scale resolution, is associated with problems based on positioning accuracy at such ultra-detailed level. The positioning of GCPs, based on field measurements by GNSS, can achieve horizontal and vertical accuracy at the centimeter scale [6]. When the GSD of the image is scaled to millimeters, the accuracy of its positioning decreases by an order of magnitude. However, achieving absolute accuracy corresponding to the resolution of the image in this type of survey is not feasible both for both technical and practical reasons. These technical restrictions are based on the nature of the GNSS positioning technology, where centimeter-scale accuracy represents the limit for practical applications $[27,28]$. These same limitations in positioning accuracy also then apply to the UAV imaging platforms, which are equipped with an onboard GNSS device and store location information in the imagery metadata. Solutions can be found in the use of another techniques for the GCP positioning, i.e., by measuring using total station in local coordinate system. The use of onboard RTK GNSS system can then significantly increase accuracy of positioning, but also the precision of flight control, assuring the correct parameters of the flight route.

Within field positioning, other limits are represented by the physical size of the instruments throughout the entire positioning process. As the surface of the alluvium is repeatedly remodeled by the fluvial activity, permanent GCPs, which can achieve absolute accuracy, are likely to be covered by fresh depositions. Therefore, various types of temporary GCPs are used for on-site positioning. The physical size of the GCP center points, as well as that of the positioning pole, do not allow researchers to obtain accuracy better than the centimeter scale, which can thus be considered to represent the practical limit for accuracy in field positioning.

The importance of these subtle differences in positioning is not relevant to the absolute location of the analyzed scene in the study area, where centimeter-scale accuracy is more than satisfactory. However, positioning differences on the scale of centimeters, together with the other factors, i.e., varying light conditions or the changing nature of the 3-D objects can be a source of differences in orthoimage, that can be translated to the granulometric differences in multitemporal analysis. The shifts in location of the source imagery below the virtual analytical grid may result in the selection of an area which is not identical at all time horizons. Therefore, the results of granulometric analysis performed on individual time slices may also differ, even when the physical environment remains unchanged. The differences in location can be tested i.e., by offsetting the sampling grid in a pattern, by the moving window analysis. The effect of the offset is illustrated by Figure 13, which depicts the selected 1-meter grid field outside the active meander zone at the two time horizons of May 2014 (Figure 13a) and September 2014 (Figure 13b), during which no physical change occurred in the given area. Here, differences in positioning reach $2.7 \mathrm{~cm}$, resulting in the slight shifting of features (Figure 13c). However, the impact on this shift is marginal, as it affects only the selected clasts at the boundary of the grid.
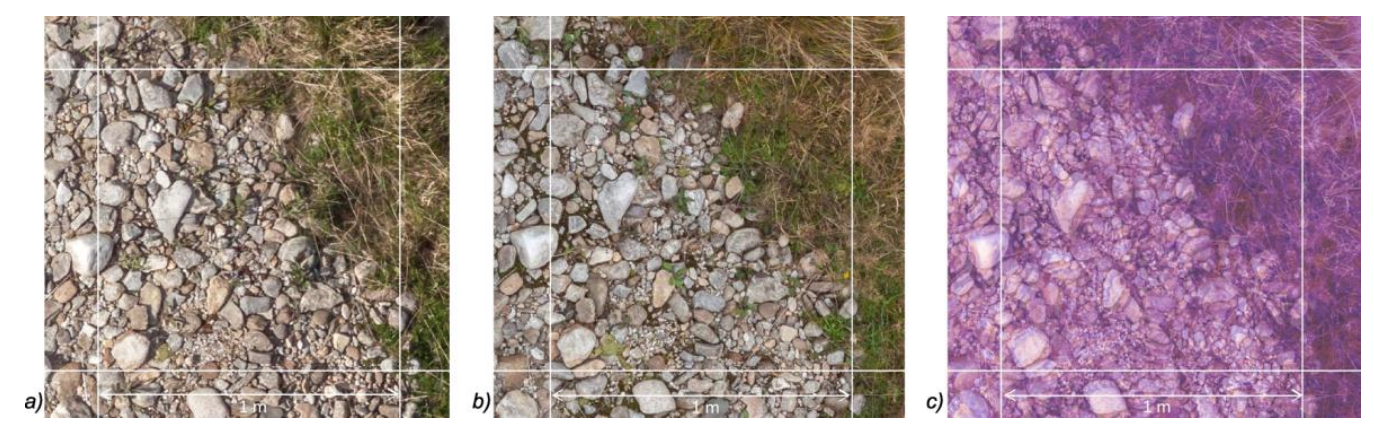

Figure 13. Differences between multitemporal grids resulting from limited accuracy of positioning: (a) Grid from May 2014; (b) grid from September 2014; and (c) difference between the two grids, marked by blue (May 2014) and red colors (September 2014). 
This phenomenon should, therefore, be taken into consideration, especially in transition zones with heterogeneous grain size structures. The uncertainty resulting from centimeter-scale differences in positioning is minimal; however, it should be considered when interpreting changes in granulometric properties on a multitemporal scale.

Despite the aforementioned uncertainty in absolute positioning, the UAV-based approach for the analysis of granulometric properties is the only reliable method for the detection of grain size structures at identical sampling sites assessed over complex areas. It is virtually impossible to use conventional methods of physical granulometry or manual optical granulometry to identify identical sampling spots over time in a riverscape remodeled by fluvial processes.

\section{Conclusions}

The paper presents a new, non-invasive technique of granulometric analysis based on the fusion of two image analysis techniques: Unmanned Aerial Vehicles (UAV)-based photogrammetry and optical digital granulometry.

This proposed technique is tested in a mid-mountain stream area with elevated fluvial activity accelerated by recurrent flooding. Measurements were obtained in 2014 and 2016 in order to track changes in the distribution of granulometric properties across a point bar which was subject to recent fluvial accumulations.

The dense point cloud and DEM, generated using Agisoft Photoscan Pro, are then post-processed using the Trimble INPHO software to obtain an orthoimage with consistent quality across the entire scene. The BaseGrain tool is used to analyze granulometric properties in $1 \mathrm{~m} \times 1 \mathrm{~m}$ segments, arranged in two transects, located at the upper and lower regions of the analyzed point bar $\mathrm{t}$ both time horizons of spring 2014 and 2016.

We further calibrate the optimum UAV flight parameters to achieve the necessary requirements of imagery resolution and coverage of the study site. For the given configuration of the imaging platform, the optimum flight altitude for imagery acquisition is defined as $4-8 \mathrm{~m}$ above the ground, which results in a GSD of 1.2 to $1.7 \mathrm{~mm}$. This level of detail is satisfactory for the identification of the finest gravel clast category, while also maintaining imaging operability to produce seamless coverage of the study area.

This granulometric analysis, based on the seamless orthoimages, yields grain size distribution values across the point bar for the two selected transects at both time horizons. This analysis allows us to correctly distinguish major grain size categories, their distributions across the alluvial point bar, and distinctions between zones of recent and old accumulations as well as their changes over time.

This proposed method of fusion of UAV photogrammetry and optical granulometry has two significant advances over geomorphological surveys: it possesses a greater analytical flexibility across multiple study sites, and it has the potential to apply multitemporal analysis to areas undergoing significant morphological changes.

These ultra-high resolution orthoimages are beneficial, as they allow workers to perform analyses in variable user-defined patterns, independent of the design of the field sampling campaign. Unlike conventional field surveys, which are based on data collection undertaken in preselected spots, using a seamless data source covers the entire study area, thus allowing researchers to design and test different patterns for granulometric analysis, designed according to the goals of their studies.

Testing the proposed workflow of UAV granulometry proves the applicability of this method for granulometric research in geomorphological studies. This method has potential for further improvements, resulting from the rapid development of imaging and data analysis technologies.

Supplementary Materials: The following are available online at www.mdpi.com/2072-4292/9/3/240/s1, Figure S1: Zoomed transect A (upper part) and B (lower part) across the point bar of Javoří brook (May 2014). From the point bar (left) to the river margin (right), alluvial deposits become progressively fresher, resulting from erosional activity, Figure S2: Zoomed transect A' (upper part) and B' (lower part) across the point bar of Javoří brook (June 2016). After the flooding in December 2015 and April 2016, the zone of fresh alluvial deposits apparently extended over the point bar. 
Acknowledgments: This research was supported by the EU COST Action ES1306 project LD15130, "Impact of landscape disturbance on the stream and basin connectivity" and the Czech Science Foundation project GACR 13-32133S. We also acknowledge the support of the long-term conceptual development of the research organisation (RVO: 67985891) of the Czech Academy of Sciences and the Internal Grant Agency of Palacky University Olomouc (IGA_PrF_2016_008).

Author Contributions: Jakub Langhammer has designed the study, selected the study area, proposed the methods and the workflow for the analysis and did the interpretation of results. Theodora Lendzioch did the granulometric calculations and analyses. Filip Hartvich did the selection of granulometric methods and Jakub Miřijovský did the UAV imaging and photogrammetric processing of imagery.

Conflicts of Interest: The authors declare no conflict of interest.

\section{References}

1. Bunte, K.; Abt, S.R. Sampling Surface and Subsurface Particle-Size Distributions in Wadable Gravel-and Cobble-Bed Streams for Analyses in Sediment Transport, Hydraulics, and Streambed Monitoring; Department of Agriculture, Forest Service, Rocky Mountain Research Station: Fort Collins, CO, USA, 2001.

2. Church, M.A.; McLean, D.G.; Wolcott, J.F. River Bed Gravels: Sampling and Analysis. Sediment Transport in Gravel-Bed Rivers; John Wiley and Sons: New York, NY, USA, 1987; pp. 43-88.

3. Folk, R.L. A review of grain-size parameters. Sedimentology 1966, 6, 73-93. [CrossRef]

4. Graham, D.J.; Reid, I.; Rice, S.P. Automated Sizing of Coarse-Grained Sediments: Image-Processing Procedures. Math. Geol. 2005, 37, 1-28. [CrossRef]

5. Butler, J.B.; Lane, S.N.; Chandler, J.H. Automated extraction of grain-size data from gravel surfaces using digital image processing. J. Hydraul. Res. 2001, 39, 519-529. [CrossRef]

6. Miřijovský, J.; Langhammer, J. Multitemporal Monitoring of the Morphodynamics of a Mid-Mountain Stream Using UAS Photogrammetry. Remote Sens. 2015, 7, 8586-8609. [CrossRef]

7. Čurda, J.; Janský, B.; Kocum, J. The effects of physical-geographic factors on flood episodes extremity in the Vydra River basin. Vliv Fyzick. Fakt. Extrem. Povodní Povodí Vydry 2011, 116, 335-353.

8. Langhammer, J.; Su, Y.; Bernsteinová, J. Runoff Response to Climate Warming and Forest Disturbance in a Mid-Mountain Basin. Water 2015, 7, 3320-3342. [CrossRef]

9. Křenová, Z.; Hruška, J. Proper zonation-An essential tool for the future conservation of the Šumava National Park. Eur. J. Environ. Sci. 2012, 2, 62-72.

10. Millidine, K.J.; Malcolm, I.A.; Gibbins, C.N. The Potential of Digital Photogrammetry for Characterising Streambed Grain-Size Distributions in Fish Habitat Studies: A Feasibility and Limitations Report; Marine Scotland-Science, Freshwater Laboratory: Pitlochry, Scotland, 2011.

11. Graham, D.J.; Rollet, A.-J.; Rice, S.P.; Piégay, H. Conversions of Surface Grain-Size Samples Collected and Recorded Using Different Procedures. J. Hydraul. Eng. 2012, 138, 839-849. [CrossRef]

12. Ibbeken, H.; Schleyer, R. Photo-sieving: A method for grain-size analysis of coarse-grained, unconsolidated bedding surfaces. Earth Surf. Process. Landf. 1986, 11, 59-77. [CrossRef]

13. Detert, M.; Weitbrecht, V. Automatic object detection to analyze the geometry of gravel grains-A free stand-alone tool. In River Flow; CRC Press: Boca Raton, FL, USA, 2012; pp. 595-600.

14. Lejot, J.; Delacourt, C.; Piégay, H.; Fournier, T.; Trémélo, M.-L.; Allemand, P. Very high spatial resolution imagery for channel bathymetry and topography from an unmanned mapping controlled platform. Earth Surf. Process. Landf. 2007, 32, 1705-1725. [CrossRef]

15. Clapuyt, F.; Vanacker, V.; van Oost, K. Reproducibility of UAV-based earth topography reconstructions based on Structure-from-Motion algorithms. Geomorphology 2016, 260, 4-15. [CrossRef]

16. Eltner, A.; Schneider, D. Analysis of Different Methods for 3D Reconstruction of Natural Surfaces from Parallel-Axes UAV Images. Photogramm. Rec. 2015, 30, 279-299. [CrossRef]

17. Westoby, M.J.; Brasington, J.; Glasser, N.F.; Hambrey, M.J.; Reynolds, J.M. "Structure-from-Motion" photogrammetry: A low-cost, effective tool for geoscience applications. Geomorphology 2012, 179, 300-314. [CrossRef]

18. Remondino, F.; del Pizzo, S.; Kersten, T.P.; Troisi, S. Low-cost and open-source solutions for automated image orientation-A critical overview. In Euro-Mediterranean Conference; Springer: Berlin/Heidelberg, Germany, 2012; pp. 40-54. 
19. Fonstad, M.A.; Dietrich, J.T.; Courville, B.C.; Jensen, J.L.; Carbonneau, P.E. Topographic structure from motion: A new development in photogrammetric measurement. Earth Surf. Process. Landf. 2013, 38, 421-430. [CrossRef]

20. Hirschmuller, H. Stereo Processing by Semiglobal Matching and Mutual Information. IEEE Trans. Pattern Anal. Mach. Intell. 2008, 30, 328-341. [CrossRef] [PubMed]

21. Hirschmuller, H. Accurate and efficient stereo processing by semi-global matching and mutual information. In Proceedings of the IEEE Computer Society Conference on Computer Vision and Pattern Recognition (CVPR 2005), San Diego, CA, USA, 20-25 June 2005; Volume 2, pp. 807-814.

22. Langhammer, J.; Česák, J. Applicability of a Nu-Support Vector Regression Model for the Completion of Missing Data in Hydrological Time Series. Water 2016, 8, 560. [CrossRef]

23. Fehr, R. Geschiebeanalysen in Gebirgsflüssen: Umrechnung und Vergleich von verschiedenen Analyseverfahren; Versuchsanst. für Wasserbau, Hydrologie u. Glaziologie: Zurich, Switzerland, 1987.

24. Sime, L.C.; Ferguson, R.I. Information on grain sizes in Gravel-Bed Rivers by automated image analysis. J. Sediment. Res. 2003, 73, 630-636. [CrossRef]

25. International Organization for Standardization. CEN 14688-1: 2002/A1: 2013: Geotechnical Investigation and Testing —Identification and Classification of Soil_Part 1: Identification and Description-Amendment 1 2013; International Organization for Standardization: Geneva, Switzerland, 2002.

26. Pix4D. Ground Sampling Distance Calculator. Available online: https://support.pix4d.com/hc/en-us/articles / 202560249-TOOLS-GSD-Calculator\#gsc.tab=0 (accessed on 15 January 2017).

27. Rieke, M.; Foerster, T.; Geipel, J.; Prinz, T. High-precision positioning and real-time data processing of UAV-systems. Int. Arch. Photogramm. Remote Sens. Spat. Inf. Sci. 2011. [CrossRef]

28. Groves, P.D. Principles of GNSS, Inertial, and Multisensor Integrated Navigation Systems; Artech House: London, UK, 2013.

(C) 2017 by the authors. Licensee MDPI, Basel, Switzerland. This article is an open access article distributed under the terms and conditions of the Creative Commons Attribution (CC BY) license (http:/ / creativecommons.org/licenses/by/4.0/). 